\title{
POSITION AND MOVEMENTS OF THE EYE IN OCULOMOTOR PARALYSIS
}

To the Editors of THE BRITISH Journal of OPHTHALMOLOGY.

DEAR SIRS.-In their note on the position of the eye in third nerve palsy, Mr. Wolff and Surgeon-Commander Heffernan raise several interesting questions. They state quite correctly that the usual description given of the position of the affected eye is "out and somewhat down or simply down and out." The illustrations, however, published in several text books show usually a relative depression of the cornea of the affected eye, which appears to be due to the photograph having been taken with the unaffected eye looking slightly upwards. The text-books are unhelpful in that the descriptions are vague and inexplicit and, an important point, do not state whether the paralysis was complete or not or in what direction the patient was looking when the picture was taken. In one text-book an illustration of bilateral IIIrd paralysis shows both corneae elevated rather than depressed. This obscurity in the text-books arises largely from the habit of copying statements from one book to another without critical examination. I found the following in two text-books :-

"Finally the eye is deviated outward and a little downward because the two muscles that are not paretic, the external rectus and the superior oblique, draw the eyeball in this direction."

"....the eyeball, which is deflected strongly outwards and somewhat down, because the two muscles not paralysed-ithe external rectus and the superior oblique-draw it in this direction."

It is not likely that in complete IIIrd palsy any apparent downward direction of the affected eye could be produced by the action of the superior oblique and the above statements must be regarded as incorrect.

The second question is:- "What are the movements of the affected eye?"

Berry (1889) explains clearly that the amount of depression possible depends on the position of the eye. If the paralysis is incomplete so that a little power remains in the medial rectus the superior oblique can come into action as a depressor. In such cases a little power might also remain in the inferior rectus. It is interesting to note that in the case described the affected eye could be brought to the midline, presumably owing to relaxation of the left lateral rectus, and yet the patient was unable to turn the cornea downwards. One would be glad to have the authors' comment on this feature of their case.

The late W. G. Sym used to pose a test question to examination candidates:- "How does the eye move in oculomotor paralysis when the patient is asked to look down?" The correct answer was "Nasal rotation of the cornea only". I have myself never seen depression of the cornea in complete IIIrd paralysis. 
The third interesting point is the absence of any affection of the optic nerve in the case recorded. It is noteworthy that in cases of a blow to the temple in which the optic nerve is damaged the motility of the eye is unimpaired and where a traumatic paralysis occurs the optic nerve escapes.

Yours faithfully,

EDINBURGH.

H. M. TRAQUaIR.

July $8,1947$.

\section{COLOUR VISION IN THE CONSULTING ROOM}

To the Editors of THE BRITISH JOURNAL OF OPHTHALMOLOGY.

DEAR SIRS.- I was pleased to see the letter from John Grieve regarding my article on colour vision, and am glad to give the explanation he requires.

The article, "Colour Vision in the Consulting Room," was a very brief résumé of some work I had done which was not published in full owing to the paper shortage, and naturally any detailed descriptions were omitted.

I made no claim that the figure of 5.5 per cent. for the gross incidence of colour defectives was anything other than the actual percentage of the subjects I had examined. These men were not chosen at random from the male population and any generalisation would have been misleading.

I consider it would have been a waste of space to describe the correct technique for using the Ishihara plates in an ophthalmological journal, and likewise considered a detailed description of the construction of the various lanterns, some of which were made from black-out shades and coffee tins, entirely irrelevant: the number and size of the apertures and the use of a rheostat appeared to be the only data necessary. The filters used approximated to those recommended by the International Committee for Aerial Navigation.

No laboratory methods could be applied to my tests, hence the title I used, and variations in colour temperature were ignored.

I hope that the résumé had made it clear that single and multilight lanterns functioned differently, the first emphasising successive contrast, the second simultaneous contrast, and/or successive, if, for the sake-of argument, one supposes that macular fixation allows only one object to be seen at a time, a point which it is not my intention to discuss.

\section{Yours truly,}

FRANK'R. NEUBERT.

HAUTERIVE,

THE QUEEN'S ROAD GUERNSEY.

July 12, 1947. 